\title{
Combined lung and liver transplantation in a girl with cystic fibrosis
}

A. Andrew Zimmerman $M D$, *

Todd K. Howard MD, $\dagger$

Charles B. Huddleston MD $\dagger$

Purpose: To describe the anesthetic considerations of a combined lung and liver transplant in a 14-yr-old girl with cystic fibrosis.

Clinical features: A 14 yr-old girl with cystic fibrosis presented for combined liver and lung transplantation. Anesthetic management was complex in that the pulmonary, hemodynamic, and hematological changes after cardiopulmonary bypass and lung transplantation made the management of the subsequent liver transplant unique. We used a moderate dose fentanyl and isoflurane anesthetic with invasive monitoring including a pulmonary artery catheter. Upon reperfusion of the new liver our patient exhibited severe pulmonary hypertension that was associated with a decrease in cardiac output and systemic hypotension. Utilizing a pulmonary artery catheter, this episode was treated with an increase of prostaglandin $\mathrm{E}_{1}\left(\mathrm{PGE}_{1}\right)$ infusion to $0.025 \mu \mathrm{g} \cdot \mathrm{kg}^{-1} \cdot \mathrm{min}^{-1}$ and the initiation of 3 $\mu \mathrm{g} \cdot \mathrm{kg}^{-1} \cdot \mathrm{min}^{-1}$ dobutamine. The pulmonary hypertension resolved and the cardiac output and blood pressure returned to baseline levels.

Conclusion: The anesthetic considerations for a combined lung and liver transplant are complex because of the interactions and alterations in cardiovascular, pulmonary and hemostatic systems. The use of a pulmonary artery catheter was critical to the management of our patient because it allowed us to accurately treat an episode of hypotension occurring during liver transplantation. This episode was secondary to acute pulmonary hypertension which is common after pulmonary transplantation but unusual during liver transplantation. It is also critical that a team approach is used to consider all of the concerns of the multiple services managing these complex patients.

Objectif : Décrire les composantes anesthésiques d'une greffe combinée du poumon et du foie chez une jeune fille de 14 ans atteinte de fibrose kystique.

Eléments cliniques : Une jeune fille de 14 ans atteinte de fibrose kystique devait subir une greffe combinée du foie et du poumon. L'anesthésie a été complexe, car les changements pulmonaires, hémodynamiques et hématologiques causés par la circulation extracorporelle et la transplantation du poumon ont influencé de façon unique la greffe du foie qui a suivi. On a utilisé une dose modérée de fentanyl et d'isoflurane et un monitorage effractif comprenant un cathéter de l'artère pulmonaire. À la reperfusion du nouveau foie, on a noté une hypertension pulmonaire sévère associée à une baisse du débit cardiaque et à une hypotension générale. Cet épisode a été traité avec une perfusion accrue de prostaglandine $E_{1}\left(P G E_{1}\right)$ jusqu'à $0,025 \mu \mathrm{g}^{\prime} \mathrm{kg}^{-1} \cdot \mathrm{min}^{-1}$ et l'administration de 3 $\mu \mathrm{g} \cdot \mathrm{kg}^{-1} \cdot \mathrm{min}^{-1}$ de dobutamine à l'aide du cathéter de l'artère pulmonaire. L'hypertension pulmonaire s'est résorbée et le débit cardiaque ainsi que la tension artérielle sont revenus à la normale.

Conclusion : La greffe combinée du poumon et du foie demande un aménagement anesthésique complexe à cause des changements cardio-vasculaire, pulmonaire et hémostatique et aux interactions entre ces systèmes. L'usage d'un cathéter de l'artère pulmonaire a été décisif, puisqu'il nous a permis de traiter efficacement l'hypotension survenue pendant la greffe du foie. Cet épisode était secondaire à l'hypertension pulmonaire aiguë, fréquente à la suite d'une greffe pulmonaire mais inhabituelle pendant la greffe du foie. Dans des situations cliniques d'une telle complexité, il est crucial de travailler en équipe afin de tenir compte de toutes les composantes des multiples services nécessaires.

From the Departments of Anesthesiology* and Surgery, † Washington University School of Medicine and St. Louis Children's Hospital, St. Louis, Missouri, USA.

Address correspondence to: A. Andrew Zimmerman MD, Department of Anesthesia, CH-05, Children's Hospital and Regional Medical Center, 4800 Sand Point Way NE, Seattle, Washington 98105 USA. Phone: 206-526-2518; Fax: 206-527-3935; E-mail: azimme@chmc.org. Accepted for publication March 17, 1999 


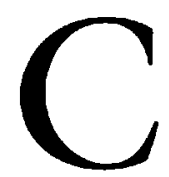

YSTIC fibrosis (CF) is an autosomal recessive disorder characterized by exocrine gland dysfunction resulting in severe chronic pulmonary disease, pancreatic dysfunction, and hepatic dysfunction. Recently, combined lung and liver transplantation has been advocated for CF patients with end-stage lung and hepatic disease. ${ }^{1}$ To date there is little information describing anesthetic considerations for this combined procedure. ${ }^{2}$ Both lung and liver transplantation, when performed separately are associated with multiple alterations in the cardiovascular, pulmonary, and hemostatic systems. We describe the case of a 14-yearold CF patient with end-stage liver and lung disease presenting for combined organ transplantation.

\section{Case report}

The patient is a 14 yr-old girl, $40 \mathrm{~kg}$, ASA physical status IV, with cystic fibrosis, who presented for combined lung and liver transplantation. She presented 12 days before transplantation with deteriorating respiratory function requiring tracheal intubation. Her past medical history included $\mathrm{CF}$ associated with severe end stage obstructive lung disease requiring lobectomy for pneumonia at nine years $\left(\mathrm{FEV}_{1}, 18 \%\right.$ of predicted value). She also had severe end stage liver disease secondary to focal biliary cirrhosis associated with portal hypertension, intermittent hepatic encephalopathy, and multiple episodes of bleeding esophageal varices. These numerous episodes of bleeding required multiple surgical procedures including, banding, sclerosis, coil embolization, and four different diverting shunts. She had no known drug allergies and was receiving multiple medications including, neomycin, spironolactone, ciprofloxacin, famotidine, ursodiol, nadolol, and vitamin $\mathrm{K}$.

On the day of the transplant, the patient was awake but anxious. The trachea had been intubated two days before the procedure secondary to tachypnea and hypoxia and she was breathing oxygen $30 \%$ with a $\mathrm{PaO}_{2}$ of $90 \mathrm{mmHg}, \mathrm{PaCO}_{2} 53 \mathrm{mmHg}$, and a $\mathrm{pH}$ of 7.37. Other laboratory values included: hemoglobin ( $\mathrm{Hgb}) 10.7 \mathrm{mg} \cdot \mathrm{dl}^{-1}$, hematocrit $33.2 \%$, platelet count $166 \mathrm{k} \cdot \mathrm{mm}^{-3}$, protime $13.1 \mathrm{sec}$, partial thromboplastin time $37.1 \mathrm{sec}$, total bilirubin $15.5 \mathrm{mg} \cdot \mathrm{dl}^{-1}$, SGOT 280 iu. $1^{-1}$, SGPT $91 \mathrm{iu} \cdot \mathrm{l}^{-1}$. Intravenous access included a 7 French double lumen central venous catheter in the left external jugular vein. She was brought to the operating room after sedation with $3 \mathrm{mg}$ midazolam $i v$ titrated over $10 \mathrm{~min}$. After placement of routine monitors (blood pressure cuff, pulse oximeter and electrocardiogram), anesthesia was induced with $2 \mathrm{mg}$ midazolam, and $20 \mu \mathrm{g} \cdot \mathrm{kg}^{-1}$ fentanyl titrated over 10 min. Neuromuscular blockade was achieved with $4 \mathrm{mg}$ pancuronium bromide. After induction of anesthesia, two $14 \mathrm{~g}$ peripheral intravenous lines were placed, a 7 FR introducer was placed in the right internal jugular vein, and a 5.5 FR oximetric pulmonary artery catheter was inserted. Due to the eventual resection of both pulmonary arteries, the pulmonary artery catheter was floated only to the central venous position at $15 \mathrm{~cm}$. Antifibrinolytic therapy was initiated with a loading dose of $240 \mathrm{mg} \cdot \mathrm{m}^{-2}$ aprotinin followed by a continuous infusion of $56 \mathrm{mg} \cdot \mathrm{m}^{-2} \cdot \mathrm{hr}^{-1}$. Anesthesia was maintained with isoflurane 0.3 to $0.5 \%$ inspired in an air/oxygen mixture and supplemental doses of fentanyl and midazolam. Volume control ventilation was delivered via the anesthesia machine (Seimens 900C) and adjusted to arterial blood gas measurements.

The initial surgical procedure was bilateral sequential lung transplant via a bilateral anterior transsternal thoracotomy incision. The hemodynamic and laboratory data are presented in Table. The patient was anticoagulated with 12,000 u heparin and was placed on cardiopulmonary bypass (CPB) via right atrial and aortic cannulae. The CPB pump was primed with crystalloid and one unit of packed red cells (PRBCs) was added because the initial hemoglobin concentration on $\mathrm{CPB}$ was $5.9 \mathrm{mg} \cdot \mathrm{dl}^{-1}$. Both lungs were resected and the donor lungs were sequentially transplanted in the left and right chest. Prior to unclamping the pulmonary arteries, an infusion of $0.0125 \mu \mathrm{g} \cdot \mathrm{kg}^{-1} \cdot \mathrm{min}^{-1}$ prostaglandin $\mathrm{E}_{1}\left(\mathrm{PGE}_{1}\right)$ was administered to prevent reperfusion injury and for its dilating effect on the pulmonary vascular resistance. ${ }^{3,4}$ The pulmonary artery catheter was then floated into the right pulmonary artery. The patient was weaned off $\mathrm{CPB}$ and required inotropic support with $7.5 \mu \mathrm{g} \cdot \mathrm{kg}^{-1} \cdot \mathrm{min}^{-1}$ dopamine. A technique of modified ultrafiltration was used to remove $1800 \mathrm{ml}$ fluid resulting in a $\mathrm{Hb}$ of $10.1 \mathrm{mg} \cdot \mathrm{dl}^{-1}$. The heparin was reversed with protamine. After adequate hemostasis was achieved, the chest was packed and left open in case exploration was needed during the liver transplant. The duration of the lung transplant was six hours and $\mathbf{3 0} \mathrm{min}$.

Prior to the liver transplant, the $\mathrm{Hb}$ was $7.3 \mathrm{mg} \cdot \mathrm{dl}^{-1}$, platelets $89,000 / \cdot \mathrm{cmm}^{-1}$, PT $17.8 \mathrm{sec}$, and PTT 102.5 sec. She was transfused with two units PRBCs and two units fresh frozen plasma (FFP). During the liver transplantation, arterial, central venous, and pulmonary artery pressures were measured as well as cardiac output and mixed venous oxygen saturations. Complete blood counts (CBCs), arterial blood gases (ABGs), and coagulation parameters were performed hourly and blood product administration was based on laboratory data 


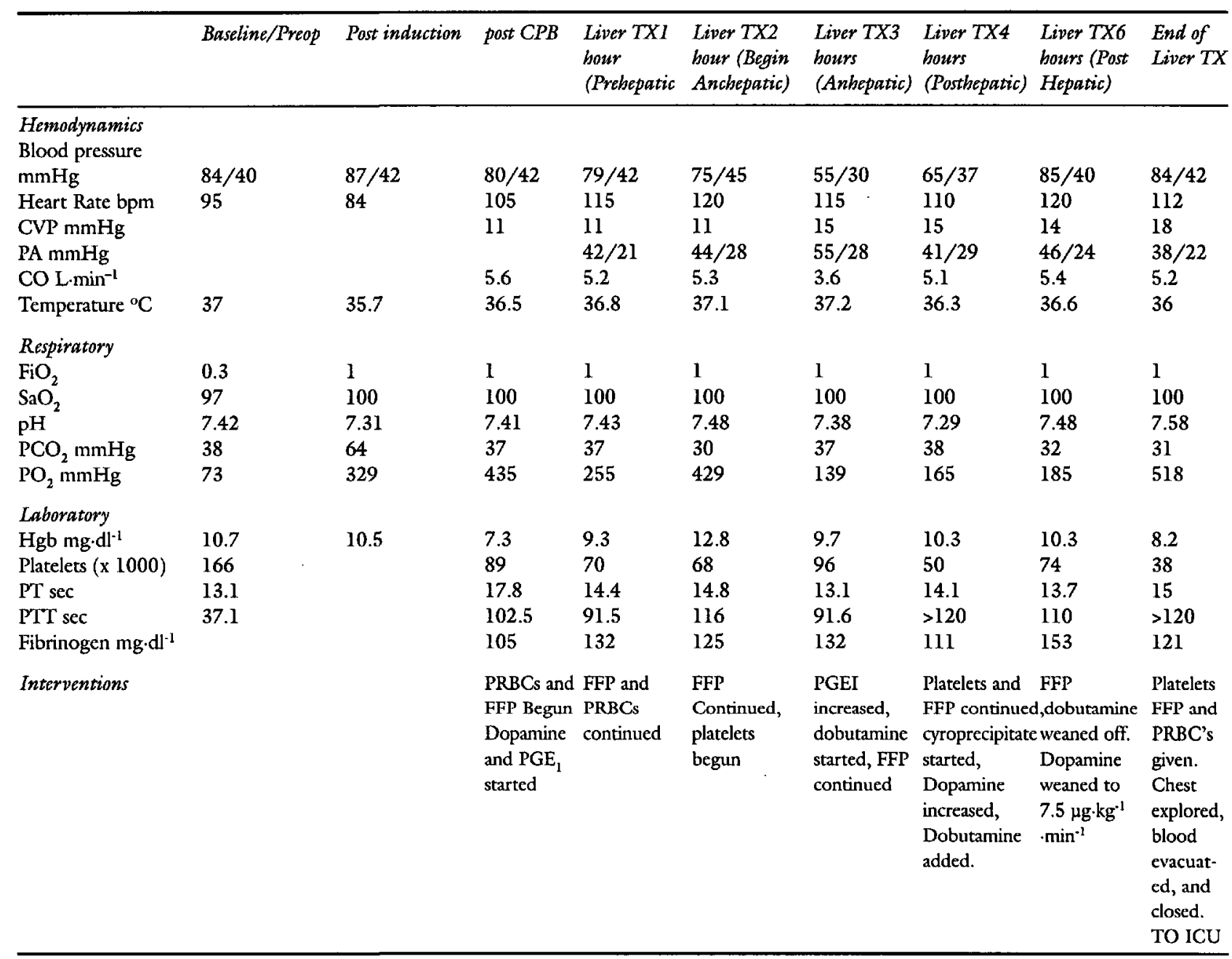

and clinical bleeding. Three hours after the start of the liver transplant, the patient became hypotensive. This was precipitated by an increase in PA pressure from 41 to $55 \mathrm{mmHg}$ (systolic) and an associated decrease in cardiac output ( $5.3 \mathrm{~L} \cdot \mathrm{min}^{-1}$ to $3.6 \mathrm{~L} \cdot \mathrm{min}^{-1}$ ) Changes also occurred in $\mathrm{MVO}_{2}(78 \%$ to $66 \%), \mathrm{PaO}_{2}(236$ $\mathrm{mmHg}$ to $139 \mathrm{mmHg}$ ), $\mathrm{PCO}_{2}$ (32 $\mathrm{mmHg}$ to 38 $\mathrm{mmHg}), \mathrm{pH}$ (7.44 to 7.29) and an increase in CVP (11 $\mathrm{mmHg}$ to $16 \mathrm{mmHg}$ ). This episode occurred about ten minutes after the reperfusion of the new liver. Dobutamine was instituted at $3 \mu \mathrm{g} \cdot \mathrm{kg}^{-1} \cdot \mathrm{min}^{-1}$ and the $\mathrm{PGE}_{1}$ infusion was doubled to $0.025 \mu \mathrm{g} \cdot \mathrm{kg}^{-1} \cdot \mathrm{min}^{-1}$. Subsequently the blood pressure improved and the PA pressures decreased to $36 \mathrm{mmHg}$ (systolic). This episode was attributed to the acidosis associated with reperfusion of the new liver. The dobutamine was subsequently weaned over three hours and the $\mathrm{PGE}_{1}$ was decreased to the pre liver transplant rate $(0.0125$ $\left.\mu \mathrm{g} \cdot \mathrm{kg}^{-1} \cdot \mathrm{min}^{-1}\right)$. At the end of liver transplantation, $\mathrm{PaO}_{2}$ decreased to $76 \mathrm{mmHg}$ without any associated hemodynamic changes, so the chest was explored. A large collection of blood was evacuated and bleeding sites were cauterized. This allowed greater expansion of the lungs and the $\mathrm{PaO}_{2}$ increased to $518 \mathrm{mmHg}$. The chest was then closed. During the entire procedure the patient received a total of eight units PRBCs, eight units FFP, six units platelets, and one unit cryoprecipitate, three litres of crystalloid and $750 \mathrm{ml}$ albumin $5 \%$. The aprotinin was discontinued at the end of the procedure, and she was transported to the pediatric intensive care unit receiving $7.5 \mu \mathrm{g} \cdot \mathrm{kg}^{-1} \cdot \mathrm{min}^{-1}$ dopamine and $0.0125 \mu \mathrm{g} \cdot \mathrm{kg}^{-1} \cdot \mathrm{min}^{-1} \mathrm{PGE}_{1}$. The total anesthesia time was $18 \mathrm{hr}$. Her post-operative course was complicated by an increase in chest tube output that required reexploration on the first postoperative day where a bleeding site was cauterized. The trachea was extubated on the third postoperative day, and she was discharged on the 18 th postoperative day. 


\section{Discussion}

Multiple organ transplantation is the only therapeutic option for some patients with systemic diseases affecting multiple organ systems. We describe the successful management of a $14 \mathrm{yr}$-old girl with cystic fibrosis who underwent combined lung and liver transplantation using a moderate dose opioid and isoflurane technique, aprotinin and a pulmonary artery catheter.

From a hemodynamic perspective, we placed a pulmonary artery (PA) catheter even though they are not routinely used in pediatric patients undergoing lung transplantation. We felt that monitoring cardiac output and PA pressures would be critical because pulmonary hypertension and graft dysfunction can occur in the early postoperative period especially after the use of cardiopulmonary bypass. ${ }^{5}$ Liver transplantation is often associated with hypotension but this is usually a result of hypovolemia, bleeding and a decrease in filling pressures. Hypotension can also be associated with venous air embolus. It would be difficult to assess hemodynamic changes accurately during liver transplantation after the use of cardiopulmonary bypass and lung transplantation without a method of measuring cardiac output and pulmonary artery pressures. The use of transesophageal echocardiography would be useful in differentiating hemodynamic changes, but is contraindicated in patients with esophageal varices. Our patient exhibited an episode of hypotension during liver transplantation which was precipitated by an episode of pulmonary hypertension. Pulmonary hypertension with an associated decrease in $\mathrm{CO}$ and systemic blood pressure is not uncommon after lung transplantation, but is not a typical cause of hypotension during liver transplantation. This episode was responsive to an increase in $\mathrm{PGE}_{1}$ and the addition of dobutamine.

In this case, as in most of our pediatric lung transplants, we used a combination of a moderate dose narcotic technique with low dose isoflurane. This anesthetic technique is also commonly used in liver transplants. The use of moderate doses of fentanyl has been shown to blunt the stress response in children with congenital heart disease and has also been shown to blunt the pulmonary vascular response to airway manipulation. ${ }^{6-8}$ Although blunting pulmonary vascular reactivity to the stress response and airway manipulation is critical during lung transplantation, there are no reports specifically examining this in the literature. Additionally, we used pancuronium bromide for neuromuscular blockade because we specifically wanted a muscle relaxant that had no histamine response and postoperative ventilation was anticipated. Nitrous oxide was avoided to prevent potential bowel distension.
Nitrous oxide can also increase the size of air emboli that have been associated with liver transplantation as well as with cardiopulmonary bypass.

An unusual aspect of this combined transplant was the management of hemostasis. At our institution, pediatric lung transplantation is always facilitated with the use of cardiopulmonary bypass. In the adult population, one lung ventilation without cardiopulmonary bypass is often the preferred technique. Liver transplantation alone is associated with severe coagulopathies including factor deficiencies and massive transfusion, but when the use of cardiopulmonary bypass is used prior to the procedure, marked changes were anticipated. A dilutional coagulopathy and thrombocytopenia secondary to cardiopulmonary bypass only exacerbates the hemostatic alterations associated with hepatic failure and liver transplantation. Our patient had moderate thrombocytopenia as well as a dilutional coagulopathy at the end of the lung transplantation which required factor replacement prior to the start of the liver transplant. We also monitored CBCs, PT, PTT, and fibrinogen hourly and tailored additional transfusion based on abnormal laboratory values and clinical bleeding. During the entire procedure the patient received eight units PRBCs, eight units FFP, six units platelets and one unit of cryoprecipitate.

Several studies have shown a considerable decrease in blood loss during lung transplantation with the use of aprotinin..$^{9-11}$ At our institution, we routinely use the antifibrinolytic agent aprotinin for pediatric lung transplantation. Antifibrinolytic agents have been implicated in hepatic vein thrombosis and their use in liver transplantation is controversial. ${ }^{2}$ After discussions with both surgical teams, we elected to use aprotinin because of the increased risk of bleeding with the combined procedures.

We have described the successful management of a 14 yr-old girl who underwent a combined liver and lung transplant. The anesthetic management for these patients should take into account the interactions and alterations in cardiovascular, pulmonary and hemostatic systems. In our case we have shown how a pulmonary artery contributed to the successful outcome. Our patient's episode of hypotension during the liver transplantation was not secondary to hypovolemia but secondary to an episode of pulmonary hypertension. It is also critical that a team approach is used to consider all of the concerns of the multiple services managing these complex patients.

\section{References}

1 Couetil JPA, Houssin DP, Soubrane O, et al. Combined lung and liver transplantation in patients with cystic fibrosis. A 4 1/2-year experience. J Thorac Cardiovasc Surg 1995; 110: 1415-23. 
2 Bund M, Seitz W, Schüfers H-J, Ringe B, Kirchner E. Combined lung and liver transplantation.

Anesthesiologic management. (German) Anaesthesist 1994; 43: 322-9.

3 Novick RJ, Reid KR, Denning L, Duplan J, Menkis $A H, M c K e n z i e F N$. Prolonged preservation of canine lung allografts: the role of prostaglandins. Ann Thorac Surg 1991; 51: 853-9.

4 Aoe $M$, Trachiotis GD, Okabayashi $K$, et al. Administration of prostaglandin $\mathrm{E}_{1}$ after lung transplantation improves early graft function. Ann Thorac Surg 1994; 58: 655-61.

5 Fullerton DA, McIntyre RC, Jr., Mitchell MB, Campbell $D N$, Grover FL. Lung transplantation with cardiopulmonary bypass exaggerates pulmonary vasomotor dysfunction in the transplanted lung. J Thorac Cardiovasc Surg 1995; 109: 212-7.

6 Hickey PR, Hansen DD, Wessel DL, Lang P, Jonas RA, Elixson EM. Blunting of the stress responses in the pulmonary circulation of infants by fentanyl. Anesth Analg 1985; 64: 1137-42.

7 Anand KJS, Hansen DD, Hickey PR. Hormonal-metabolic stress responses in neonates undergoing cardiac surgery. Anesthesiology 1990; 73: 661-70.

8 Anand KJS, Hickey PR. Halothane-morphine compared with high-dose sufentanil for anesthesia and postoperative analgesia in neonatal cardiac surgery. $\mathbf{N}$ Engl J Med 1992; 326: 1-9.

9 Jaquiss $R D B$, Huddleston $C B$, Spray TL. Use of aprotinin in pediatric lung transplantation. J Heart Lung Transplant 1995; 14: 302-7.

10 Kesten $S$, de Hoyas A, Chaparro $C$, Westney $G$, Winton $T$, Maurer JR. Aprotinin reduces blood loss in lung transplant recipients. Ann Thorac Surg 1995; 59: 877-9.

11 Peterson KL, DeCampli WM, Feeley TW, Starnes VA. Blood loss and transfusion requirements in cystic fibrosis patients undergoing heart-lung or lung transplantation. J Cardiothorac Vasc Anesth 1995; 9: 59-62.

12 Porte $R J$. Coagulation and fibrinolysis in orthotopic liver transplantation: current views and insights. Semin Thromb Hemost 1993; 19: 191-7. 